\title{
Derivações prefixais do tipo não-x, quase-x, além-x e mil-x na poética cabralina: marca de expressividade na neologia estilística
}

DOI: http://dx.doi.org/10.21165/el.v48i3.2346

\author{
Rosana Maria Sant'Ana Cotrim
}

\section{Resumo}

Este artigo apresenta uma análise de criações lexicais encontradas na poética de João Cabral de Melo Neto que, concebidas como neologia estilística, engendram grande expressividade no discurso em que se inserem. São unidades léxicas criadas por processo de derivação prefixal, as quais comportam uma estrutura singular pela ligação de bases nominais e verbais a elementos prefixais não constituídos pelos tradicionais prefixos. Partindo-se do pressuposto de que a poética cabralina é pautada no rigor da "forma construída" pela manipulação da linguagem, compreende-se que elas revelam uma marca de expressividade, pelo inusitado das combinações empregadas, capaz de fazer sentido tanto pelo que as unidades lexicais criadas enunciam, quanto pela exploração do próprio processo derivacional que as cria.

Palavras-chave: criação lexical; neologia estilística; expressividade.

1 Universidade Federal de Mato Grosso (UFMT) Rondonópolis, Mato Grosso, Brasil; rocotrim@outlook.com.br; https://orcid.org/0000-0002-4818-7543 


\section{Dérivations préfixaux du type non-x, quasi-x, à part-x, et mil-x dans la poétique cabralienne : marque de l'expressivité à là néologie stylistique}

\section{Résumé}

Cet article présente une analyse des créations lexicales retrouvés dans la poétique de João Cabral de Melo Neto que, crées comme de néologie stylistique, engendrent grande expressivité au discours en qu'elles s'inscrivent. Ce sont des unités lexicales crées par processus de dérivation préfixal, auxquelles comportent une structure singulière par la liaison de bases nominaux et verbaux à des éléments préfixaux non constitués par les préfixes traditionnels. On part de l'idée que la poétique cabralienne est réguler par une rigueur de la « forme construite » par la manipulation du langage, on comprend que telles manifestations révèlent une marque d'expressivité, par l'inhabituel des combinaisons employées, capables de donner un sens à la fois à ce que les unités lexicales établies énoncent et à l'exploitation du processus de dérivation même qui les crée.

Mots-clés: création lexical ; néologie stylistique ; expressivité.

\section{Apontamentos iniciais}

As criações lexicais, aplicadas ao universo literário e, portanto, concebidas como neologia estilística, vêm atendendo às necessidades expressivas de escritores desde os tempos mais remotos da história das línguas. Segundo Martins (2000), na Idade Média foram notáveis os efeitos humorísticos alcançados a partir do emprego de neologismos nas poesias satíricas, nas farsas e nas comédias.

Porém, em se tratando de uma literatura brasileira, propriamente, é a partir do século XIX que há, por parte de escritores, uma exploração mais intensa do léxico virtual, configurada pela criação lexical, na busca de atender às necessidades expressivas em suas obras. Por exemplo, no Romantismo, as criações lexicais apareciam nas obras ficcionistas e poéticas buscando imprimir subjetividade e pompa linguística com o emprego de radicais e afixos em novas formas. Já no Simbolismo, elas resultavam do empenho para se obter um léxico que se adequasse às novas situações que o poeta descortinava dentro de si. Nesse contexto, as criações lexicais muitas vezes ajudaram a formar as imagens e os símbolos da poética simbolista.

Mas foi, sobretudo, no Modernismo, quando os escritores buscavam reforçar seu intento criativo e, principalmente, demonstrar uma nova postura linguística frente aos seus antecessores, que as criações lexicais oriundas do domínio literário ganharam relevo e reconhecimento. Todavia, muito mais do que, em princípio, a crítica e o aviltamento da língua oficial para a implantação de uma língua que se pretendia nacional e, daí, a 
construção da identidade brasileira, o emprego dos neologismos na literatura modernista como um todo e no seu transcorrer logrou magníficos resultados expressivos.

É, pois, neste contexto que se entende inserida a poética de João Cabral de Melo Neto, poeta teoricamente enquadrado na primeira fase modernista brasileira e reconhecido como um dos maiores poetas do século $X X$, que recorre sistemática e discursivamente às criações lexicais em sua produção poética (COTRIM, 2012).

Este trabalho tem por objetivo, portanto, apresentar alguns casos de derivação prefixal encontrados na poética cabralina, mais especificamente, as derivações prefixais com estrutura tipificada em não-x, quase- $x$, além-x e mil-x, com vistas a demonstrar o modo como elas fazem sentido no enunciado e revelam uma marca de expressividade no discurso em que se inserem, tanto pelo que enunciam nos respectivos contextos, quanto pela própria estrutura que comportam.

Tais derivações prefixais fazem parte de um corpus, denominado Neologismos na Poética Cabralina (Corpus NPJC)², constituído metodologicamente a partir da recolha, classificação e análise de unidades léxicas criadas, por diferentes processos de formação de palavras e concebidas como neológicas, nas obras poéticas do referido escritor. Para a recolha, classificação e análise das unidades léxicas criadas, fundamentou-se nos Estudos do Léxico, complementando-se com as abordagens da Estilística Léxica para a demonstração da expressividade por elas alcançadas. E, para a atestação da neologicidade das criações lexicais cabralinas, adotou-se o critério lexicográfico, a partir da constituição de um corpus de exclusão, composto de quatro dicionários de língua de grande circulação na língua portuguesa contemporânea e posterior à produção do poeta.

A apresentação deste trabalho segue um percurso que dispõe, respectivamente, de alguns apontamentos sobre o fenômeno da criação lexical no processo de evolução linguística; uma explanação sobre os meandros da expressividade da neologia estilística no discurso literário; uma abordagem sobre a poética cabralina e sua trajetória de depuração; uma perspectiva de análise dos casos de derivação prefixal recorrentes, tipificados e contextualizados nas obras do referido poeta, com respectiva demonstração do modo como eles operam no seu discurso; e, finalmente, algumas considerações sobre os resultados do fenômeno na poética cabralina, seguidas das referências que fundamentam esta investigação.

2 O Corpus NPJC, donde extraímos e adaptamos o trabalho para esta publicação, é parte constitutiva dos resultados de nossa tese de doutorado, intitulada As criações lexicais na poética de João Cabral de Melo Neto: contribuições aos estudos do léxico no discurso literário, defendida junto à Universidade Estadual de São Paulo (UNESP), campus de Araraquara. 


\title{
O fenômeno da criação lexical
}

Uma das características universais da linguagem humana é a mudança. O contrário disso, ou a falta de evolução de uma língua, significa sua morte. E, embora se tenha ciência de que a mudança alcance todos os componentes linguísticos, sem dúvida, o lexical é o que mais reflete a evolução das línguas, haja vista sua incrível suscetibilidade à expansão.

De acordo com Correia e Lemos (2009, p. 10), isso acontece por duas razões:

\begin{abstract}
[...] por um lado, porque, não sendo o componente lexical um componente tão estruturado como, por exemplo, os componentes fonológico ou sintático, e sendo o conhecimento lexical mais consciente, porque constituído não só por regras, mas, sobretudo, por itens, a mudança pode ocorrer de modo mais 'livre' e rápido, afetando unidades e não tanto a estrutura do léxico; por outro lado, sendo através das unidades lexicais que designamos os itens da realidade envolvente e que traduzimos o conhecimento que temos dessa realidade, é natural que o componente lexical reflita de forma mais direta todas as alterações, toda a evolução que o meio vai sofrendo.
\end{abstract}

Assim, diante da inegável evolução linguística, se algumas unidades do léxico caem em desuso - os arcaísmos -, outras vão sendo criadas - os neologismos -, cuja existência configura o fenômeno da criação lexical: a neologia.

A neologia pode ser concebida, então, sob duas formas: como a capacidade natural de criação de novas unidades lexicais a partir de regras de produção disponíveis no sistema lexical e como o estudo (observação, registro e datação, descrição e análise) dos neologismos que surgem nas línguas, isto é, dos produtos da criação lexical.

A primeira forma de concepção refere-se à definição das virtualidades e está inteiramente ligada à capacidade de renovação do léxico de uma língua. A segunda remete a definição às unidades lexicais ligadas ao universo das coisas, às modalidades do pensamento, a todo movimento do mundo e da sociedade. Tendo em vista a necessidade do estudo da neologia lexical, estende-se também ao levantamento dos neologismos surgidos dentro de um período preciso da vida da comunidade linguística.

Levando em conta a primeira concepção, ou seja, a neologia compreendida como demonstração da "criatividade" lexical, Guilbert (1975) concebe as seguintes formas de neologia: a neologia denominativa que, como sugere o nome, corresponde à necessidade de denominação de novas experiências (fatos ou objetos); a neologia de língua que, por corresponder apenas ao exercício da competência derivacional do falante, é compreendida como unidade do discurso; e a neologia estilística, correspondente a uma 
forma diferenciada da expressividade da palavra em si ou de uma frase pela presença de uma palavra nova, com o objetivo de traduzir de maneira original ou inédita certa visão pessoal do mundo.

Em sentido amplo, evidenciam-se duas fases na criação lexical: uma que se relaciona ao momento da enunciação da unidade lexical criada no discurso, e outra, ao momento do seu emprego pelos locutores da comunidade linguística. Considerada a distinção entre língua (tomada como sistema) e discurso (tomado como o uso que dela se faz), as primeiras realizações dos neologismos ocorrem sempre ao nível do discurso. Porém, dadas certas circunstâncias, algumas vão se repetir a ponto de integrarem o léxico da língua ${ }^{3}$ e outras permanecerão no nível do discurso.

Dentre os tipos de neologia, a denominativa é a que apresenta maior probabilidade de compor o sistema linguístico. E, por outro lado, a neologia de língua, pelo seu estatuto virtual e, principalmente, a neologia estilística, pelas suas características e particularidades, raramente incorporarão o léxico de uma língua.

No que se refere especificamente à neologia estilística, ela está mais afeita a linguagens como a literária, a jornalística, a afetiva, a irônica, a satírica ou outras de natureza similar, sempre na busca de provocar sentido(s) e efeito(s) de sentido na enunciação. Portanto, ela, de fato, não carreia uma inserção no léxico da língua, mas tão somente a possibilidade de engendrar expressividade no discurso a cada nova realização, a cada nova leitura.

Ocorre que, caminhando na contramão do modo de compreensão da neologia denominativa ou mesmo da neologia de língua, a neologia estilística aceita regras próprias. Em outras palavras, em tipos específicos de discurso, como o literário, o neologismo, como qualquer outra marca discursiva, aparece sempre ligado a uma situação de enunciação. Isso possibilita o estabelecimento, por exemplo, dentro de uma obra literária ou no conjunto de obras de um escritor, de traços recorrentes capazes de demarcar uma preferência que a caracterize e, como tal, se converta em estratégia discursiva, imprimindo sentido(s) e efeito(s) de sentido no discurso em que se insere. Isto é, promovendo expressividade.

3 Em regra, a entrada da unidade léxica no sistema linguístico é geralmente oficializada pelo seu registro em dicionário de língua; o que também marca o momento em que a unidade léxica deixa de ser neológica. 


\section{Os meandros da expressividade nas/das criações lexicais literárias}

A expressividade relaciona-se à escolha. Todo processo comunicativo, seja ele falado ou escrito, é geralmente marcado por uma intenção que, por sua vez, é mediada por uma escolha, tanto em função da consciência que se tem do sistema linguístico no processo enunciativo ${ }^{4}$, quanto da consciência que se supõe que o destinatário tenha do enunciado.

A escolha, segundo Cressot (1976, p. 1), é um "fato estilístico" de ordem, ao mesmo tempo, linguística, psicológica e social porque regula os modos de expressão. Ou seja, a emissão de um enunciado exige uma relação com o enunciatário que leve em conta fatores como faixa etária, sexo, nível de formação, entre outros.

Nesse sentido, perpassada pela noção de discursividade, a expressividade ganha consistência no interior dos discursos, mediada, pois, pela intenção, pelas escolhas, pelas subjetividades que a constituem, pelas situações de uso da língua e aplicadas a gêneros discursivos específicos que demandam olhares particularizados no âmbito dos estudos linguísticos.

Concebendo a neologia estilística como um tipo de criatividade e, consequentemente, renegando da compreensão cartesiana de língua, os postulados guilbertianos apontam para uma mudança de perspectiva do componente lexical, cuja articulação entre o linguístico e o social vincula a linguagem à ideologia.

Nesse contexto, a compreensão é a de que a escolha lexical, que se refere ao modo como se faz uso do léxico real ou virtual da língua dentro do discurso, é determinada por diferentes variáveis de ordem intra e extralinguística. Assim, galgando a função privilegiada de veiculadora de ideologia, a palavra, além de unidade do léxico, assume a condição de unidade léxica dentro do discurso:

\footnotetext{
4 A referência ao processo enunciativo é feita, aqui, pela sua relação com o discurso a partir da explicação dos termos adjacentes enunciado e enunciação. O enunciado inscreve-se na materialidade discursiva, isto é, no texto; e a enunciação é a instância de mediação que assegura a possibilidade de o texto transformar-se em discurso, ou seja, de a língua poder ser discursivizada. Assim, se o discurso põe a língua em funcionamento, nesse sentido, ele é o lugar onde se manifesta o sujeito da enunciação - com a escolha da pessoa, do espaço, do tempo e dos elementos que vão figurar no texto, a figurativização - e onde podem ser recuperadas as relações entre o texto e o contexto socio-histórico que o produziu. A forma de passagem do sistema para o discurso é, pois, pela enunciação, ou seja: actorializando, temporalizando e espacializando. Se o sujeito põe a língua em funcionamento, não há como pensar a linguagem sem uma visão enunciativa.
} 
A palavra é, com efeito, um elemento lexical que se define através das realizações do discurso [...]. A transformação do esquema de frase em frase realizada supõe a comunicação entre um sujeito falante que enuncia a sequência sintática real e um ouvinte presente ou fictício que a recebe. Cada um destes seres de carne e de sangue é modalizado psicológica e sociologicamente, animado de motivações particulares dentro do diálogo; a língua aparece, a partir de então, como um instrumento de comunicação de seres pensantes, membros de uma comunidade linguística, dentro de uma situação dada e não mais como uma estrutura abstrata. (GUILBERT, 1975, p. 126, tradução nossa) ${ }^{5}$.

Por essa concepção, a palavra deixa de ser uma unidade dentre a totalidade do léxico da língua para tornar-se um elemento de elocução passível de variação quanto ao tipo de discurso e de possibilidade de nuançar a expressão.

De modo geral, uma escolha pode ser de diferentes ordens, relacionando-se, por exemplo, à forma de tratamento utilizada, à organização do discurso (direto ou indireto), do período (coordenação ou subordinação) ou da frase (ordem direta ou inversa), à estrutura textual adotada, à seleção lexical, etc. Mas, em se tratando da escolha lexical no discurso literário, podem-se empregar palavras gramaticais com valor lexical, escolher uma palavra pelo seu valor emotivo ou avaliativo, optar por um ou outro sinônimo em função do contexto, empregar uma palavra constitutiva do arcabouço lexical ou criar uma unidade léxica nova que venha satisfazer determinada situação expressiva.

Assim, compreendidas como escolha, as criações lexicais literárias manifestam-se impregnadas da expressividade e da discursividade que lhe são intrínsecas.

O ramo da Linguística que se ocupa do estudo da expressividade da criação lexical é a Estilística Morfológica. Esta disciplina nasce com o objetivo de compreender os efeitos da expressividade resultantes das alterações na/da morfologia da unidade léxica criada, por meio dos processos que as formam.

Martins (2000, p. 110-111) assevera que

5 No original: "Le mot est en effet part un élément lexical qui se définit à travers les réalisations du discurs [...]. La transformation du schéma de frase en frase réalisée suppose la communication entre un sujet parlant qui énonce la séquence syntaxique réelle et un auditeur présent ou fictif qui la reçoit. Chacun de ces êtres de chair et de sang est façonné psycologiquement et sociologiquement, animé de motivations particulières dans le dialogue; le langage apparait des lors comme l'instrument de communication d'êtres pensants, membres d'une communauté linguistique, dans une situation donné et non comme une structure abstraite". 
[...] os aspectos morfológicos da língua são muito importantes para a linguagem expressiva e [...] devem ser estudados, ainda que apareçam permeados com a semântica e a sintaxe. Aliás, que valores expressivos podem ser sentidos fora da frase ou do discurso, se é a frase a unidade do discurso, se só falamos por meio dela? Mas nem por isso a expressividade da frase ou do enunciado deixa de dever aos valores fônicos e mórficos. A ideia de que vocábulos que não se incorporam na língua não têm interesse estilístico é bem discutível. Primeiramente, porque não podemos antever o destino dos vocábulos forjados por um escritor ou por uma pessoa qualquer. Demais eles evidenciam as potencialidades dos processos de renovação do léxico e dos elementos formadores (lexemas e morfemas), que são integrantes da língua.

Por esse crivo das potencialidades dos processos de criação lexical passa a noção de competência lexical. Toda unidade léxica nova, por ser oriunda do discurso, denota uma competência lexical (ou derivacional) do falante que viabiliza todo processo criativo da/ na língua em uso. Segundo Corbin (1984, p. 6, tradução nossa),

A competência derivacional é, pois, o domínio das regras que definem aquilo que é possível e impossível linguisticamente, o critério de exclusão seria a violação de uma ou de várias propriedades da regra aplicada. O saber lexical convencional é o domínio de escolha linguisticamente arbitrária, do normativo, que define aquilo que é possível e impossível dentro do uso social do léxico [.... $]^{6}$.

Quer dizer que todo sujeito falante é dotado de uma competência lexical que lhe permite criar e compreender uma infinidade de palavras criadas, além de fazer julgamentos sobre a gramática delas. Mas também de um saber lexical convencional que autoriza, entre outros comportamentos, julgar como aceitáveis palavras construídas não atestadas; escolher entre várias afixações concorrentes a que melhor se encaixa numa base, quando uma regra linguística não consegue explicar a seleção atestada; escolher, entre várias propriedades linguisticamente equivalentes para uma mesma formação o gênero (masculino, feminino) ou o traço (+ humano, - humano) dos afixos; identificar semanticamente vários derivados da mesma base; interpretar as construções com base nas idiossincrasias; etc.

Não há como negar, portanto, a estreita relação entre os dois níveis, visto que o saber lexical convencional atua crendo fornecer um modelo para a competência lexical.

6 No original: "La compétence dérivationnelle est donc le domaine des règles, qui définissent ce qui est possible et impossible linguistiquement, le critère d'exclusion étant la violation d'une ou de plusieurs propriétés de la règle apliquée. Le savoir lexical conventionnel est le domaine du choix linguistiquement arbitraire, du normative, qui définit ce qui est possible et impossible dans l'usage social du lexique [...]". 
Porém, é a situação discursiva que vai determinar a possibilidade de distinção entre ambos, permitindo, em contrapartida, melhor situar as noções de palavra possível e de sentimento linguístico.

Isso porque o conhecimento lexical de todo falante comporta dois tipos de informações: uma regular, constituída por regras que the permitem apreender e produzir estruturas inéditas, bem como identificar e atribuir novos significados às já existentes; e uma idiossincrática, constituída pelas unidades lexicais adquiridas ao longo da vida em função de sua idade, sexo, nível educacional, lugar de origem, hábitos, interesses, etc. Tais informações, mediadas pela competência e pelo saber lexical do falante, mobilizam regras lexicais que são marcadas por uma relação de regularidade entre uma base e seu produto.

Pode-se dizer, portanto, que as criações lexicais funcionam como unidades discursivas responsáveis por traduzir a expressão do sentimento de quem as produz, mas também, podem assinalar posições ideológicas, apontar estratégias discursivas e, até mesmo, promover resultados estéticos capazes de consolidar estilos de um autor ou de uma época.

Demais, em função da expressividade, elas podem atender a regras próprias. O que na neologia denominativa ou na neologia de língua pode representar restrições e bloqueios (SANDMANN, 1991)7 , na neologia estilística pode significar uma forma de expressividade capaz de imprimir uma ou mais marcas no discurso.

\section{A poética cabralina: uma trajetória de depuração}

Tradicionalmente, a poética cabralina é reconhecida pelo seu rigor formal, o que situa João Cabral de Melo Neto junto a significativas tendências do pensamento da arte moderna, herdeira, entre outros, de Mallarmé e Valéry. De fato, a revalorização do cuidado com a linguagem e a proposição de uma expressão poética mais disciplinada outorgamIhe uma composição originalmente mais racional que, somada a uma perfectibilidade da forma, ao que tudo indica, proposital e conscientemente, ele cultiva.

Demais, a poética cabralina perpassa um universo temático considerado substantivo, recoberto pela abordagem, principalmente, da seca (nordestina e outras) com suas mazelas; do sertanejo nordestino e das coisas em seu derredor; de Pernambuco (e do Recife), onde nascera o poeta; do Rio Capibaribe (e outros rios pernambucanos); dos modos de criação, pela sua compreensão metalinguística do fazer poético; do cultivo da cana-de-açúcar, dos latifúndios canavieiros e dos engenhos de açúcar; entre outros.

7 Segundo Sandmann (1991, p. 14-15), "Por restrições se entendem as limitações a que uma regra está sujeita por sua própria natureza. [...] Bloqueio [...] é o fenômeno da não-produção de uma unidade lexical complexa em virtude da existência anterior de outra forma". 
Esse procedimento poético constituído em torno do trabalho formal com a linguagem e da crítica histórico-social mobilizada por uma forma escritural também crítica, define à poética cabralina um percurso muito particular, que o poeta parece ter perseguido durante toda sua vida. Por outro lado, embora se tenha reconhecido certa dificuldade de se fazer considerações seguras acerca dessa produção tida como substancial e formalmente construída, a teoria e a crítica literárias têm observado tendências que norteiam esse fazer poético e sustentam essa trajetória de aprimoramento da forma poética.

Nunes (2000, p. 37) caracterizou esse procedimento na obra de João Cabral como "ascese que depura pacientemente a linguagem até neutralizar nela o sujeito como Eu, para assegurar à mesma linguagem a comunicabilidade por meio da forma construída", que dá a cada poema uma arquitetura única, cujo funcionamento verbal precisa ser desvendado pelo leitor.

Para Nunes (2000), esse processo de depuração na obra do poeta está associado a três procedimentos escriturais fundamentais. O primeiro deles é a predominância do uso de nomes (em geral concretos),

[...] designativos de coisas naturais ou fabricadas, de lugares, paisagens, espécies ou categorias de pessoas ou atividades, que acabam por se tornar [...] objetos temáticos, peças fundamentais de um repertório-léxico, vindo quase sempre no título das composições. (NUNES, 2000, p. 38).

De certa forma, tal procedimento colabora para a criação de um universo poético marcado pela busca da exatidão e por certa referencialidade, modo caracteristicamente cabralino de vincular sua linguagem ao mundo.

A constituição da metalinguagem representa o segundo dos procedimentos elencados pelo teórico, cuja "transposição de qualidade das coisas humanas para as naturais, e vice-versa" (NUNES, 2000, p. 40) produz um efeito de oscilação entre o concreto e o abstrato. Na verdade, isso é o que define a pedra-de-toque da poesia de João Cabral: o verso consciente que repudia uma poética ao acaso ou inspirada.

O terceiro dos procedimentos consiste, por sua vez, no trato da linguagem relacionada à interioridade (NUNES, 2000). Tal procedimento, como observa o teórico, aparece associado à paixão amorosa e à sedução do corpo. Isso é relevante para a temática do feminino também presente na obra cabralina, principalmente em seus últimos livros.

No que se refere ao emprego da metáfora e do símile, isso constitui, por vezes, um modo de tratar um dado tema e, ao mesmo tempo, de falar do tratamento que é dado ao tema, como um procedimento metalinguístico. 
Tudo isso, na verdade, consiste na revelação da universalidade alcançada pela poesia em João Cabral que parece decorrer da tensão entre o olhar objetivo do poeta para uma realidade determinada (e linguisticamente recriada) e a subjetividade que sustenta esse olhar. Ou que é representada por um conjunto de opções e escolhas individuais, operadas no âmbito da criação linguística e, portanto, centradas em escolhas de ordem enunciativa, seletiva e combinatória. Isto é, em escolhas autorais, que apontam, paradoxalmente, para a presença do poeta e constroem, de certo modo, uma persona de escritor, pautada na objetividade e no caráter substantivo da linguagem, em oposição ao sentimentalismo.

Segundo Moisés (1989), a emoção, componente indispensável à existência da poesia, aparece de forma contida, concentrada na poética de João Cabral. De modo que a palavra, ganhando espessura, concretude, perde em quantidade para enriquecer-se em qualidade. Por isso, pela ótica do poeta, a emoção vem fortalecida por um processo rigoroso de pensamento "científico", "arquitetônico" (ou de engenheiro), símile do filosófico. Diz, ainda, o teórico, que não fosse a engenhosidade do poeta, sua composição seria apenas um exercício descritivo ou uma prosa metrificada e não poesia.

Há que se considerar, diante disso, que a poética de João Cabral se constrói por meio da constante afirmação de que o poema se faz a partir de um olhar crítico do poeta, voltado ora para a linguagem, ora para a realidade social ou, em geral, para ambas, pois que para o poeta

A poesia [...] é a exploração da materialidade das palavras e de possibilidades de organização de estruturas verbais, coisas que não têm nada a ver com o que é romanticamente chamado inspiração ou mesmo intuição. [...] [é a] exploração emotiva do mundo das coisas [e] rigorosa construção de estruturas formais lúcidas, lúcidos objetos de linguagem. (MELO NETO, 1998, p. 135).

É essa postura, afinal, que sustenta a relação de pertencimento de João Cabral ao moderno e o coloca como um dos maiores poetas do século XX (BOSI, 2001), ainda que, por vezes, sua poética apareça meio à deriva (LIMA, 2000), junto às tendências da poesia brasileira de seu tempo. É também essa postura que sustenta o procedimento de manipulação e construção da linguagem e, por essa via, corrobora o recurso às criações lexicais na poética cabralina.

\section{A expressividade das derivações prefixais cabralinas}

Na língua portuguesa, a derivação, por sua produtividade e regularidade, é considerada um tipo padrão de criação de palavras e, portanto, é muito empregada na neologia denominativa. Isso se deve principalmente ao fato de que ela gera combinações possíveis e sentidos previsíveis a partir dos afixos e das bases selecionadas para atender às necessidades comunicativas da língua comum. 
Segundo Correia e Lemos (2009), a derivação é aparentemente o processo mais disponível para a construção de palavras não só na língua portuguesa, mas em todas as línguas românicas. Além da quantidade de palavras oriundas deste processo já registradas nos dicionários, é relevante a potencialidade da regra para a construção de novas unidades léxicas por derivação.

Essa produtividade dos processos derivacionais vincula-se diretamente ao teor de generalidade de suas funções sintático-semânticas (BASÍLIO, 2007). Algumas funções como a negação, o grau, a designação de indivíduos ou entidades abstratas são bastante comuns e, consequentemente, mais produtivas, enquanto os processos que apresentam funções mais particularizadas e, portanto, menos comuns, são, na mesma proporção, menos produtivos. Além disso, de modo geral, a derivação revela-se um processo bastante regular.

Nesse sentido, pode-se considerar, com Correia e Lemos (2009) que: i) na formação da nova unidade por derivação deve haver apenas uma unidade de significação lexical que é a base da derivação à qual se junta um afıxo (prefixo ou sufixo) ou dois (prefixo e sufıxo, no caso da derivação parassintética); ii) o número de afıxos derivacionais de uma língua é um conjunto limitado e que, além disso, a derivação é um processo governado por regras que permitem: a) determinar a categoria da base, b) determinar a categoria do derivado e c) prever o significado do derivado a partir dos dois elementos anteriores; iii) o prefixo corresponde a antigas preposições e advérbios latinos e gregos; iv) o prefixo tem um conteúdo semântico menos gramatical e, em vista disso, é mais facilmente perceptível do que o sufixo, gerando situações em que é difícil distinguir entre prefixos e elementos de composição.

Ora, se comparada à composição, cujo número de unidades que podem servir de bases de compostos é praticamente ilimitado, assim como a possibilidade de suas combinatórias, visto que seu emprego pode mudar seu sema em cada enunciado, a derivação confırma sua regularidade e produtividade.

Demais, no caso específico da derivação prefixal, ou prefixação, em que o prefixo exerce a função de acrescentar outras significações à base, ela organiza-se em torno dos seguintes eixos semânticos:

negação / oposição / privação - exs.: in-(infeliz), não-(não-alinhado), des-(desfazer), a- (acéfalo), anti- (anti-imperialista), contra- (contra-manifestação);

localização espácio-temporal - exs.: ante- (antecâmara, antenupcial), pré- (prénatal), pós- (pós-doutoramento), sub- (subsolo), sobre- (sobreloja); 
quantificação / intensificação / avaliação - exs.: hipo- (hipotensão), hiper(hipertensão), bi- (bimotor), micro- (microssegundo), tetra- (tetraplégico), super(super-interessante), mega- (megaconcerto). (CORREIA; LEMOS, 2009, p. 31).

Ou seja, ao que parece, em princípio, este tipo de formação de palavras tende a limitarse e, nesse sentido, a atender às necessidades básicas de criação lexical da/na língua comum.

Ocorre que, por outro lado, aplicada a discursos singularizados como o poético, a derivação prefixal pode revestir-se de características peculiares para compor um quadro que favorece a consubstanciação da expressividade da neologia estilística.

Ora, se na composição a variabilidade dos elementos participa na definição de seus traços, na derivação prefixal a escassez de prefixos pode configurar a necessidade do surgimento de um novo morfema prefixal. Em outras palavras, determinadas circunstâncias enunciativas, pela falta de um elemento prefixal institucionalizado que lhes dê sustentação discursiva na criação da unidade nova, induzem a utilização de unidades, em geral portadoras de informação gramatical, essencialmente de função adverbial ou preposicional, para recobrir esse papel.

É o caso, por exemplo, das unidades léxicas criadas em NPJC: não higiênico, não-uva, não-verso, não-andaluz, não canavieiro, quase feltro, quase metal, quase palha, quase animal, quase beata, quase-sono, quase senzala, quase barbante, quase raça, quase lua, quase esquina, quase pez, quase mucosa, além-olho, além-mártir, mil folheiro, milvestir, mil-nacional, milver e milpesado.

Esta análise considera tais criações lexicais como estruturas formadas por processo de derivação prefixal, a partir da ligação de prefixos constituídos por advérbios e numerais com valor adverbial a bases nominais e verbais. Nos respectivos contextos, elas exercem papel de substantivos, adjetivos e advérbios. Compreende-se que tanto a enunciação de cada uma quanto a recorrência a esse tipo de construção demonstram uma escolha do poeta e concorrem para a busca de expressividade em seus respectivos contextos e no discurso como um todo.

É importante frisar que, de modo geral, esse tipo de construção vem sendo empregado com frequência cada vez maior no domínio discursivo literário, a partir dos movimentos e tendências modernistas. Segundo Alves (2002, p. 28), contemporaneamente, esse tipo de criação lexical parece revelar um desejo de economia discursiva por parte do falante, haja vista que uma construção prefixal torna-se mais econômica do que uma construção sintática negativa, como se vê nas comparações seguintes: 'policiais não-violentos' X 'policiais que não são violentos', ou em 'entidades ligadas ao sem-terra' $X$ 'entidades ligadas àqueles que não possuem terra'. 
No caso específico das formações com não-, de acordo com Ferreira (2010, p. 1450), elas ocorrem na língua a partir do século XX, especialmente no pós-guerra, com sentido, em geral, de 'negação', 'privação', 'destituição', 'ausência' ou 'inexistência (de algo); também em formações com significado próprio em determinada área de conhecimento, como nos exemplos: não agressão, não combatente, não eu e não violência.

Mas o assunto é controverso. As gramáticas e dicionários descrevem o fenômeno de modo ambíguo, às vezes considerando tais elementos como prefixos, às vezes como elementos de composição (como advérbios). O Vocabulário Ortográfico da Língua Portuguesa (VOLP, 2009) adota-os como prefixos, apesar de excluir esse tipo de formação do emprego do hífen. Porém, alerta Henriques (2009) que tal atitude, em decorrência do fator compulsório da lei ortográfica, coloca em xeque o valor prefixal de um elemento que se separa de seu radical por um espaço em branco.

Tomemos alguns exemplos ${ }^{8}$ destes casos de derivação prefixal na poética cabralina, com respectivas explanações demonstrativas de sua expressividade no lugar em que figuram.

Em não-uva, pela unidade léxica criada a partir da ligação de não- (adv. originário do latim non), com valor prefixal, assim como nas demais não-higiênico, não-verso, não-andaluz e não canavieiro, o enunciador compõe a imagem negativa resultante, entre outras coisas, da crítica social de denúncia, muito representativa na poética cabralina. Observe-se que, no discurso, participam da construção dessa imagem da negatividade outros semas negativos, como nada, goro (adj.), vazio, gotas:

1. "Os vazios do homem, ainda que sintam / a plenitude (gora mas presença) / contêm nadas, contêm apenas vazios: / [...] e dela copiam certamente a estrutura: / toda em grutas ou em gotas de vazio, / postas em cachos de bolha, de não-uva." (AEPP, VII, p. 31).

Nas unidades lexicais criadas além-olho e além-mártir, o enunciador emprega o advérbio além- com valor prefixal, ligado a bases substantivas. Segundo Alves (2002), a opção por bases substantivas parece também revelar o mesmo princípio da economia discursiva que simplifica e condensa a proposição adjetival ou adverbial por meio da derivação prefixal. Nas palavras da autora: "Em termos da gramática gerativa [...] as frases desprovidas de prefixo são mais complexas e mais longas; na estrutura de superfície, o prefixo torna-as mais econômicas." (ALVES, 2002, p. 28-29).

8 Com relação aos exemplos, duas considerações são importantes para a compreensão desta análise. Uma delas é que, por se tratarem de excertos da poética de João Cabral, eles apresentam os versos separados por (/) e as estrofes por (//), de acordo com convenção literária. A outra é que a referência à obra do poeta da qual foram extraídos os excertos é demonstrada pelas letras iniciais dos respectivos títulos dos livros em que figuram e do volume em que estas se enquadram nas respectivas coletâneas, as quais constam das referências deste trabalho. 
Nos respectivos contextos, ambas as unidades criadas exercem papel de substantivo, mas suas respectivas estruturas simplificadas são impregnadas da circunstanciação intensificadora peculiar dos advérbios.

Em além-olho, a unidade léxica criada nomeia uma forma de ver, cujo alcance é maior do que o normal. Ela permeia um contexto em que o enunciador retrata um país em que a seca remete ao nordeste brasileiro:

2. "Nem o mar é de água: é de zinco, / tecto ondulado, estendido / até o alémolho, no areal / de um país praia integral." (MT. VII, p. 56).

Em além-mártir, o enunciador nomeia uma forma de ser que é superior à convencional. A unidade foi criada num contexto que retrata a história do religioso e revolucionário recifense Frei Caneca e revela a importância deste no cenário histórico brasileiro:

3. "Talvez sentisse que o mártir /tem sempre um lado podrido / e que ser eleito mártir / vem com a mania ou o vício, // enfim, com o gosto de crer-se / já um além-mártir, messias:" (MT, VII, p. 89).

As construções a partir do prefixo quase- ora qualificam nomes, ora implicam modificações circunstanciais a verbos e adjetivos. Em sua função adverbial, quase significa "perto, aproximadamente" e esse sentido se estende ao prefixo que dele é originário.

Em quase feltro, a unidade criada refere-se ao substantivo substância, atribuindo-lhe uma qualificação modificada pelo papel adverbial do prefixo. No enunciado, ela atribui uma característica ao material que compõe o objeto "faca", dado seu papel e função na vida do homem sertanejo:

4. "Mas quer durma ou se apague: / ao calar tal motor, / a alma inteira se torna / de um alcalino teor // bem semelhante à neutra / substância, quase feltro, / que é a das almas que não / têm facas-esqueleto." (UFSL, VI, p. 188).

Em quase palha, a unidade criada cumpre um papel adverbial, referindo-se ao verbo desdobrar para indicar o modo como a ação verbal se processa. No enunciado, ao referirse ao litoral pernambucano, ela sugere a repetição contínua e intensa das ondas que provoca uma mistura revoltosa e espumante de água e areia, cuja coloração e farfalhar lembram a palha. 
5. "O mar se estende pela terra / em ondas que se revezam / e se vão desdobrando até / ondas secas de outras marés: // as da areia, que mais adiante / se vão desdobrando nos mangues, / que se desdobram (quase palha) / num capim Lucas, de limalha," (Q, VI, p. 223-224).

Em quase-sono, a unidade criada apresenta uma modificação circunstancial ao verbo viajar, em que seu prefixo age sob a influência de seu papel adverbial como um modalizador delimitador do substantivo a que se refere. No enunciado, ele circunscreve o alcance aproximativo da circunstância em que a prosa, representada metafórica e metalinguisticamente pela imagem da viagem, acontece. Isto é, ela fornece subsídios que compõem a descrição do modo contínuo e monótono, a ponto de provocar entorpecimento, que se realiza a prosa em relação à poesia:

6. "O prosador tenta evitar / a quem o percorre esses trancos / da dicção da frase de pedras: / escreve-a em trilhos, alisando-a, // até o deslizante decassílabo / discursivos dos chãos de asfalto / que se viaja em quase-sono, / sem a lucidez dos sobressaltos." (MT, VII, p. 73-74).

Nas criações lexicais mil folheiro, milvestir, mil-nacional, milver e milpesado, a formação se dá a partir da ligação do prefixo mil- a bases adjetivas e verbais, as quais determinam a categoria gramatical das unidades criadas, nos respectivos contextos. E, em todas elas, mil- desempenha um papel periférico modificador.

Encontrando respaldo na teoria funcional, esta análise compreende que o prefixo milresulta de um processo anterior de recategorização da unidade léxica mil, que considerou a sua função adverbial dentro do texto, conquanto tradicionalmente ela seja classificada como numeral, ou como substantivo, referindo-se ao elemento numérico deste valor.

Segundo Neves (2000), a concepção funcional adota uma orientação teórica que contempla a "língua em uso" e que, para tanto, baseia-se em dois pontos fundamentais: i) que a unidade maior de funcionamento é o texto e ii) que os itens são multifuncionais.

No primeiro ponto está em jogo a construção do sentido na interpretação das categorias linguísticas que não pode prescindir da investigação de seu comportamento na unidade maior - o texto - que é a "real unidade de função". No segundo, que o princípio da multifuncionalidade - chave para uma interpretação funcional da linguagem - aceita que muitos dos constituintes de uma construção entrem em mais de uma configuração construcional.

Do ponto de vista semântico, mil- tem papel intensificador tanto quando se relaciona aos elementos nucleares de base verbal em vestir e ver, quanto os de base adjetival em 
folheiro e nacional e tem papel qualificador quando se relaciona com o elemento nuclear de base adjetiva participial em pesado. Conforme Neves (2000), os advérbios modificadores afetam o significado do elemento sobre o qual incidem, fazendo uma predicação sobre as propriedades desses elementos, de modo a modificá-los, seja intensificando, seja qualificando ou modalizando.

Em milvestir, o prefixo mil- liga-se a uma base verbal e funciona como um modificador intensificador da ação de vestir. Com a unidade criada, o enunciador completa o efeito da imagem de "saia folhuda" que se deve fazer da palha da cana quando ainda está no pé, isto é, antes de seu corte na lavoura. Compreende-se que ela contribui sobremaneira na composição da temática do cultivo da cana-de-açúcar:

7. "A cana-de-açúcar, tão pura, / se recusa, viva, a estar nua: / desde cedo, saias folhudas / milvestem-Ihe a perna andaluza." (AEF, VII, p. 114-115).

Em milver também há uma ligação do prefıxo a uma base verbal. A unidade criada faz parte de um contexto em que o enunciador retrata o cortejo de condução de Frei Caneca à forca. Ela reforça a aflição ou agonia do personagem em ter visto inúmeras vezes as ruas, as calçadas, as fachadas das casas, etc. do Recife, porém sem a mesma concepção de mundo e de vida a qual passa a ter dentro da cela ambulante que o conduz para a forca (e para a morte):

8. - - Dentro desta cela móvel, / do curral de gente viva, / dentro da cela ambulante / que me prende mas caminha, / posso olhar de cada lado, / para baixo e para cima. / [...] Parece que melhor vejo, / que levo lentes na vista; / se antes tudo isso milvi, / as coisas estão mais nítidas." (AF, VII, p. 175).

Já em mil-nacional, o prefixo liga-se a uma base adjetiva e funciona, no enunciado, como um intensificador da qualidade atribuída ao mar que, por ser "puro", passa a ser objeto de defesa da Alfândega que o protege da "mistura" e "contaminação" com a água mulata. Ou seja, a unidade léxica criada remete o enunciatário à ideia de desprovimento de jurisdição do alto-mar e, portanto, de despertencimento deste a uma ou outra nacionalidade. Essa imagem do mar é criada em comparação aos rios, em especial os rios do Recife, que acolhem o ribeirinho, com suas pessoalidades, suas subjetividades e, portanto, as marcas que os individualizam:

9. "Falam da Inspeção de Saúde / que (como a Alfândega racista / defende o mar mil-nacional / da água mulata) em nada fia." (AEF, VII, p. 136).

Também em mil folheiro, o prefixo funciona como intensificador do adjetivo a que se liga. No contexto, o adjetivo folheiro pode ser compreendido na acepção de "boa aparência", 
"vistoso", "airoso", "garrido". No enunciado, a unidade léxica criada demonstra um efeito de amplificação desse atributo o qual a mangueira do sertão árido nordestino não tem, já que nada lá se encorpa, nem fumaça, nem vegetação:

10. "Onde tampouco a fumaça encorpa muito; / onde nem pode o barroco mil folheiro / da mangueira matriarca, corpopulenta," (AEPP, VII, p. 6).

Por fim, em milpesado, o prefixo também se liga a uma base adjetiva e funciona como um modificador qualificador que pode ser substituído por "bem". A unidade léxica criada, no universo metalinguístico da criação poética, direciona a apreciação do enunciador para o tipo de "palavra" que deverá ou poderá "romper" a folha em branco, dando preferência às de peso ou importantes para aquele ato criativo:

11. A folha em branco é a tradução / mais aproximada do nada. / Por que romper essa pureza / com palavra não milpesada?" (A, VII, p. 248).

\section{Considerações finais}

Neste trabalho, buscou-se evidenciar a importância das criações lexicais literárias que, concebidas como neologia estilística, vêm despontando no âmbito dos estudos lexicais, não obstante a sua rara incorporação ao léxico da língua, dadas suas peculiaridades discursivas.

Para tanto, apresentou-se alguns casos de criação lexical encontrados na poética de João Cabral de Melo Neto, formados por processo de derivação prefixal, com uma estrutura tipificada e recorrente em sua obra. Demais, procurou-se demonstrar, pela sua análise, 0 modo como elas engendram sentido(s) e efeito(s) de sentido nos respectivos contextos em que aparecem, e como elas consubstanciam uma marca de expressividade na poética cabralina.

A análise aponta, enfım, que tais casos de derivação prefixal atendem aos propósitos de manipulação da linguagem e engenhosidade que ajudam a compor o universo temático e discursivo em que se assenta a linguagem cabralina e, desse modo, participam ativa e efetivamente do processo de "construção da linguagem", de que fala o próprio poeta (MELO NETO, 1998) e também para a "ascese que depura [...] a linguagem [até se chegar à] forma construída", de que fala Nunes (2000, p. 37), acerca da construção poética cabralina. 


\section{REFERÊNCIAS}

ACADEMIA BRASILEIRA DE LETRAS. Vocabulário Ortográfico da Língua Portuguesa. 5. ed. 2009.

ALVES, I. M. Neologismo: criação lexical. 2. ed. São Paulo: Ática, 2002.

BASÍLIO, M. Teoria Lexical. 8. ed. São Paulo: Ática, 2007.

BOSI, A. História concisa da literatura brasileira. 38. ed. São Paulo: Cultrix, 2001.

CORBIN, D. Méthode en Morphologie Dérivationnelle. Revue Cahiers de Lexicologie, Paris, v. XLIV, p. 3-17, 1984.

CORREIA, M.; LEMOS, L. S. P de. Inovação lexical em português. v. 4. Lisboa: Edições Colibri, 2009.

COTRIM, R. M. S. As criações lexicais na poética de João Cabral de Melo Neto: contribuições aos estudos do léxico no discurso literário. 2012. Tese (Doutorado em Linguística e Língua Portuguesa) - Faculdade de Ciências e Letras de Araraquara, Universidade Estadual Paulista, Araraquara, 2012.

CRESSOT, M. Le style et ses techiniques: précis d'analyse stylistique 3. ed. Paris: Presses Universitaires de France, 1976.

FERREIRA, A. B. de. Dicionário Aurélio da Língua Portuguesa. 5. ed. Curitiba: Editora Positivo, 2010 (Edição comemorativa dos cem anos de Aurélio Buarque de Holanda Ferreira).

GUILBERT, L. La créativité lexicale. Paris: Librairie Larousse, 1975.

HENRIQUES, C. C. A nova ortografia: o que muda com o acordo ortográfico. 5. ed. Rio de Janeiro: Elsevier Editora, 2009.

LIMA, L. C. da C. João Cabral: poeta crítico. Revista Colóquio / Letras, Lisboa, n. 157/158, p. 45-60, 2000.

MARTINS, N. S. Introdução à Estilística: a expressividade na língua portuguesa. 3. ed. São Paulo: T. A. Queiroz Editor, 2000. 
MELO NETO, J. C. de. Prosa. Rio de Janeiro: Nova Fronteira, 1998.

MELO NETO, J. C. de. A educação pela pedra e depois. v. 1. Rio de Janeiro: Nova Fronteira, 1997a.

MELO NETO, J. C. de. Serial e antes. v. 2. Rio de Janeiro: Nova Fronteira, 1997b.

MOISÉS, M. A literatura brasileira através dos textos. São Paulo: Cultrix, 1989.

NEVES, M. H. de M. Gramática de usos do português. São Paulo: Editora UNESP, 2000.

NUNES, B. João Cabral: filosofia e poesia. Revista Colóquio / Letras, Lisboa, n. 157/158, p. 37-44, 2000.

SANDMANN, A. J. Competência lexical: produtividade, restrições e bloqueio. Curitiba: Editora de UFPR, 1991. 